\title{
SEED LONGEVITY OF DOMINANT PLANT SPECIES FROM DEGRADED SAVANNA IN SEMI-ARID TANZANIA
}

\author{
HVM Lyaruu
}

Department of Botany, University of Dar es Salaam, P. O. BOX 35060, Dar es Salaam, Tanzania. lyaruu@botany.udsm.ac.tz

\begin{abstract}
Artificially buried seeds were followed by periodic exhumation and germination during 21 months in Kondoa Irangi Hills, central Tanzania. Viable seeds from thirteen selected species were buried in polythene envelopes at a depth of $15 \mathrm{~cm}$ below woodland vegetation. Lethal germination, fungal decay and insect infestation were singled out as the most important contributors to loss of viability among seeds. Hierarchical clustering based on a seed's mean viability, seed shape and presence or absence of dispersal appendages, produced three distinct groups: (1) non-dormant seeds (2) seeds with enforced dormancy and (3) seeds with seed coat imposed dormancy. The low decay constant of some species is an indication of their abilities to form persistent seed banks. The intermittent and extended germination of seeds of the same species from the same batch shown by some species may be regarded as an ecological adaptation to prevent synchronous germination in unpredictable harsh environments, whereas prompt germination of some Acacia seeds may be viewed as a strategy to avoid seed predation in the soil. Seed dormancy, which predicts seed longevity, is strongly dependent on seed moisture content and partly on other environmental factors, notably low temperatures, light and increased carbon dioxide levels.
\end{abstract}

\section{INTRODUCTION}

Knowledge of longevity of buried seeds is important for predicting responses of ecosystems to management and catastrophic changes (Roberts 1981) and may play an important role in the conservation and restoration of plant communities (Bakker 1989). To remain viable in the soil, seeds must possess mechanisms that keep them alive and at the same time prevent them from germinating. As a result, seed dormancy, quiescence and also ability of dormant seeds to detect and respond to appropriate germination cues are inherent properties of most viable seed banks. Harper (1957) distinguished three kinds of dormancy as innate, induced and enforced dormancy. Innate dormancy is caused by endogeneous factors such as embryo immaturity, or presence of internal inhibitors and hard seed coats. Induced dormancy develops in seeds when an adverse factor such as drought acts upon them to produce a state of suspended animation which persists even after the causal factor has ceased its action. Enforced dormancy is imposed by exogeneous factors, such as low temperatures, light and increased levels of carbon dioxide and lasts on as long as the external factor acts upon the seeds. The form of dormancy possessed by seed, will determine if species can form transient or long-term persistent seed bank (Thompson et al. 1997).

Artificial seed burial experiments have revealed that seed longevity increases with increasing depth of burial (Kivilaan and Bandurski 1981, Tsuyuzaki 1991). This is because the fluctuating temperatures and the low levels of carbon dioxide which occur near the surface are the main dormancy releasing factors in the soil. High temperatures are known to break seed dormancy in some species (Schafer and Chilcote 1970), but can induce dormancy in seeds of other species. 
Information on seed longevity in the soil can be obtained conventionally by sampling the soil seed bank at different soil depths and preventing influx of new seeds into the area by covering the sampled area, followed by controlled germination and re-sampling for a period of time (Roberts 1963), or through artificial seed burial and periodic exhumation of seeds (Demel and Granström 1997).

Seed shape is a useful predictor of seed longevity in the soil (Thompson et al. 1993). They use a quotient which they refer to as "variance" that expresses how diaspores deviate from being spherical. It is shown that small round seeds (i.e. compacted seeds without appendages for dispersal) tend to be much more long-lived in the soil compared with elongated seeds. This is related to the ease with which small seeds infiltrate the soil and escape predation. Many important weeds possess small and compact seeds.

There is no information regarding longevity of seeds in semi-arid Tanzania. Therefore the aim of this study was to determine the longevity of seeds of selected species in such environment. This study was conducted in the Kondoa Irangi Hills in Dodoma Region of central Tanzania (hereinafter called KIH). Among species included in this study were Acacia species which are keystone species in African savannas. These were Acacia seyal Del., Acacia tortilis (Forsk.) Hayne s.1., Faidherbia albida (Del.) A. Chev.(syn: Acacia albida) and Acacia saligna (Lab.) Wendl. The choice of other leguminous species Abrus precatorius L., Cassia occidentalis L., Crotalaria kirkii Bak. and Tephrosia villosa (L.) Pers, was based on their potential for nitrogen mineralization, which is important for rehabilitating degraded vegetation, and partly on their dominance in the study area. Seeds from the early successional pioneer shrub, Dodonaea angustifolia L. f., which readily colonises various parts of this degraded vegetation, were also studied. Bidens pilosa L., Conyza pyrhopappa L. and Vernonia cinerascens Sch.-Bip. also were included to represent the family Asteraceae. Withania somnifera (L.) Dunal of the family Solanaceae was included to diversify the number of families studied.

\section{MATERIAL AND METHODS \\ Brief description of the study area and species}

$\mathrm{KIH}$ can be regarded as a focal point of restoration activities dealing with reclamation of degraded and marginal lands in Tanzania (Mbegu and Mlenge 1984, Christiansson et al. 1993). For detailed description of KIH see Lyaruu (1995). The overall climate of the area is semi-arid to more or less sub-humid at high elevations. It has a weakly bimodal annual precipitation of 400 - $800 \mathrm{~mm}$ (Ngana 1992) but precipitation is greater in the elevated parts of Kondoa Irangi. The rainy season extends from late November to May and it comes in the form of short intense storms. The soils are texturally coarse loamy sands to sandy loams (Mbegu and Mlenge 1984), but in flatter areas black cotton soils (vertisols) are common. Seeds used in this study were collected randomly throughout $\mathrm{KIH}$ but were buried below ground in one site in woodland vegetation. The soils of this woodland vegetation can be described as free-draining sandy loams.

Seed collection, viability test and experimental set-up

Thirteen species included in this study were selected from four families representing mainly dominant trees and shrubs in the study area, i.e.: Leguminosae (8), Asteraceae (3), Sapindaceae (1) and Solanaceae (1). Naturally dried seeds were collected between September and October 1994 in Kondoa and were stored at room temperature before they were used in March 1995. Before storage, seeds damaged by insects were sorted out and removed. Seeds were considered to be viable if they appeared healthy, intact and could resist deformation when pressed between the fingers. Before the experiment was initiated, an indication of viability for 
each species with large seeds was obtained by cutting through the endosperm of twenty seeds followed by the 2, 3, 5-triphenyltetrazolium chloride (TTC) staining procedure (Roberts 1972). For small seeds, viability was assessed by direct germination of twenty seeds placed between blotting paper in petri dishes in the laboratory. Twenty seeds from each of selected thirteen species (=260 seeds) were placed in $5 \times 10$ $\mathrm{cm}$ polythene envelopes. The seeds were mixed with a reasonable amount of soil enough to keep the envelopes open after burial. The envelopes were not sealed to allow free circulation of air and were buried with their open ends pointing downwards. Ten such envelopes were buried at a depth of $15 \mathrm{~cm}$ below ground in woodland vegetation, assuming that amenable conditions may not trigger germination from this depth. While keeping the remaining envelopes in position, one envelope of each species was exhumed at a time after $3,6,9$, 12 and 21 months and the contents inspected. It was intended to monitor the experiment for a period of four years, but since all seeds had died by the time of the fifth excavation, the experiment was abandoned. The early death of seeds was attributed to lethal germination, fungal decay and insect infestation which were singled out as the most important contributors to the loss of viability among seeds. The seeds were sorted out to separate the dead from living seeds, and if possible to establish the cause of their death. The apparently viable seeds were then sown in sterilised soil in the greenhouse, and were watered at least twice daily. For each species, the time when germination started for each species, the number of germinated seeds, and the time required for complete germination were recorded. Seeds that did not germinate after six months of watering were mechanically scarified and germinated.

\section{Data analysis}

Due to skewness in distribution, the data were log-transformed before statistical treatment. ANOVA using the GLM procedure in SAS (SAS Inst. 1990) followed by Duncan's Multiple Range Test to compare significance levels among means were performed on the groups obtained from hierarchical clustering. Mean viabilities for each pair among the species studied were compared using a Paired t-Test. Hierarchical clustering of groups was performed using the programme MINITAB Version 10xtra (1995) for dendrograms and Euclidean distances (complete linkage) method. The variables included in the cluster analysis were species' mean viability, variance, and presence or absence of dispersal appendages. The procedure adopted to calculate seed variance (Thompson et al. 1993) was as follows:

- Calculation of mean length (L), width (W) and depth/breadth (D) of ten diaspores per species under the binocular stereomicroscope.

- Dividing each of the three values by the biggest value (which was generally length). The three quotients were summed up and divided by three to give a mean value $\mathbf{X}_{1}$, i.e. $X_{1}=(L / L+W / L+D / L) / 3$

- The deviations of $\mathbf{L} / \mathbf{L}, \mathbf{W} / \mathbf{L}$ and $\mathbf{D} / \mathbf{L}$ from the mean value $\mathbf{X}_{1}$ were calculated, squared and summed up to give a value $\mathbf{X}_{2}$ which was finally divided by three to obtain the variance.

The rate of deterioration of seeds in the soil was calculated from the relationship $\mathbf{S}=\mathbf{S}_{\mathbf{o}}$ $\mathbf{e}^{- \text {gt }}$ (Roberts and Dawkins 1967), where $\mathbf{S}$ is the number of viable seeds in the soil at time $\mathbf{t}, \mathbf{S}_{\mathbf{0}}$ is the number of seeds at the start of the experiment and $\mathbf{g}$ is a decay constant which is species specific. This relationship thus assumes that seed viability in the soil declines exponentially with time (Cook 1980). 


\section{RESULTS}

Causes of viability losses among species Three major sources of viability loss of the buried seeds were identified: lethal or in situ germination, fungal infection with subsequent rotting and insect infestation. It may be assumed that seeds found missing in some envelopes had been predated or secondarily dispersed. Lethal germination was common in the seeds of Acacia saligna, Acacia seyal, Cassia occidentalis, and Faidherbia albida, while rotting as a result of fungal attack was common in Abrus precatorius, Bidens pilosa, Conyza pyrhopappa, Tephrosia villosa, Vernonia cinerascens and Withania somnifera. Seeds of Acacia tortilis, Crotalaria kirkii and Dodonaea angustifolia succumbed to insect damage.

\section{Seed viability and cluster delimitation}

Pairwise comparisons of mean viabilities of all species and t-Test values are presented in Table 1 . The mean viability is explained by seed variance $\left(R^{2}=0.67\right)$ by a linear relationship y $=0.839-3.107 x$. More spherical seeds had higher viability compared with more elongated seeds (Fig. $1)$.

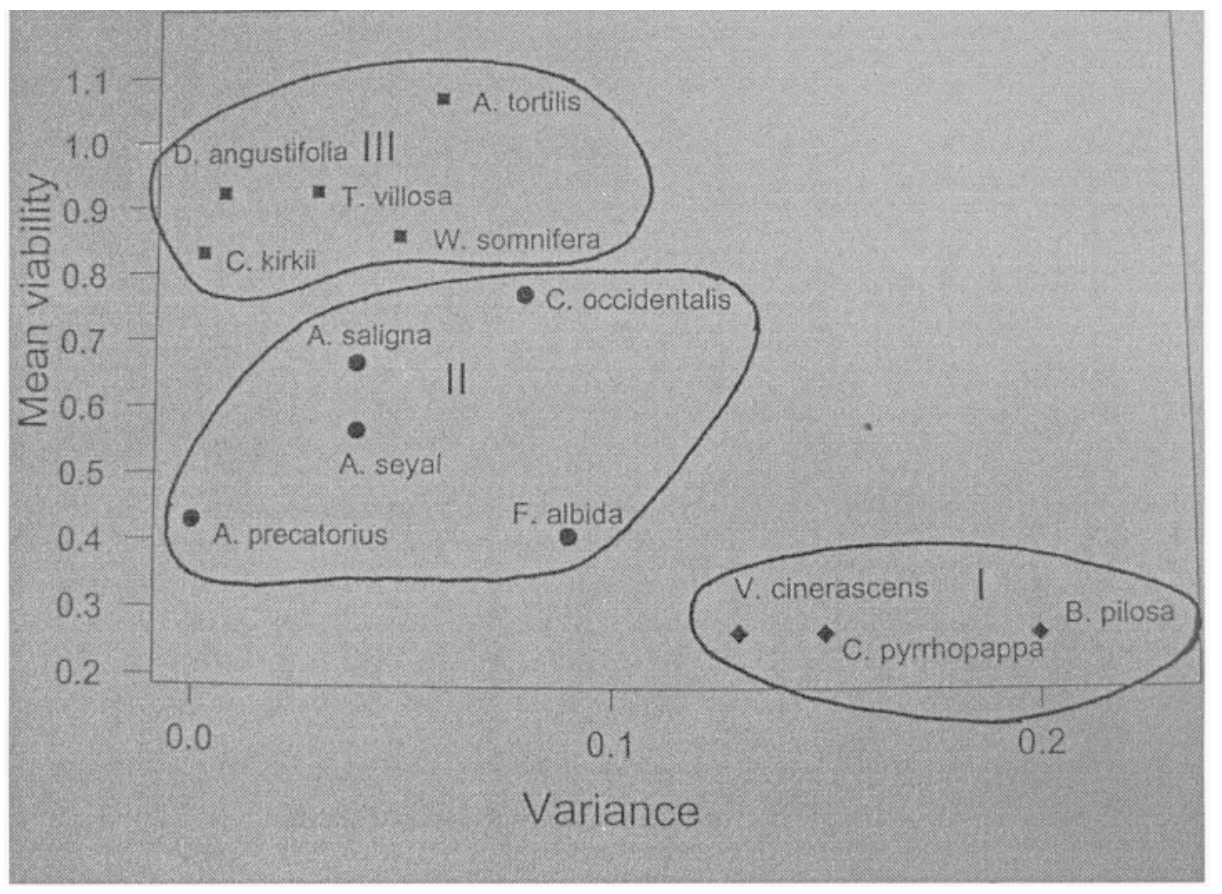

Figure 1: Variation in mean variance and mean viability (log-transformed data) of the species studied. The clusters correspond to the groups in Fig. 2.

Hierarchical clustering delimited three significantly different groups (Fig. 2). Oneway ANOVA results followed by Duncan's Multiple Range Test indicated that mean viability was significantly different between the groups $\left.\mathrm{F}_{[210]}=33.62, \mathrm{p}<0.001\right)$ and increased in the order Group III > Group II > Group I. Variance was significantly different between the groups $\left(\mathrm{F}_{[2} 10\right]=16.47, \mathrm{p}<$ $0.001)$; but only group I was significantly different from the other two groups. 
Group I- This is composed of three members of the family Asteraceae which are ornamented with dispersal appendages. These species did not survive in the soil and showed $100 \%$ loss of viability after three months burial and are likely to possess a transient seed bank in the sense of Thompson and Grime (1979).

Table 1: $\quad$ Matrix with Paired t-Test results to compare mean ( \pm s.e) viabilities of species studied except for the species with very short-lived seeds.

\begin{tabular}{|c|c|c|c|c|c|c|c|c|c|}
\hline \multicolumn{10}{|l|}{$\begin{array}{l}\text { Species } \\
\text { viability }\end{array}$} \\
\hline Falb & & & & & & & & & $4.8 \pm 3.9$ \\
\hline Apre $2.09^{*}$ & & & & & & & & & $7.6 \pm 3.3$ \\
\hline Asal $1.62^{\text {ns }}$ & $0.60^{\mathrm{ns}}$ & & & & & & & & $6.7 \pm 3.7$ \\
\hline Ckir $3.12^{* *}$ & $1.08^{\mathrm{ns}}$ & $1.65^{\mathrm{ns}}$ & & & & & & & $9.0 \pm 3.4$ \\
\hline Asey $1.64^{\mathrm{ns}}$ & $0.44^{\mathrm{ns}}$ & $0.14^{\mathrm{ns}}$ & $1.5^{\mathrm{ns}}$ & & & & & & $7.0 \pm 4.2$ \\
\hline Cocc $2.81^{* *}$ & $0.88^{\mathrm{ns}}$ & $1.42^{\mathrm{ns}}$ & $0.14^{\mathrm{ns}}$ & $1.24^{\mathrm{ns}}$ & & & & & $8.8 \pm 4.2$ \\
\hline Tvil $4.61^{* * *}$ & $2.63^{* *}$ & $3.16^{* *}$ & $1.54 \mathrm{~ns}$ & $2.91^{* *}$ & $1.60^{\mathrm{ns}}$ & & & & $11.0 \pm 3.4$ \\
\hline Dang $4.72^{* * *}$ & $2.37^{* *}$ & $3.30^{* *}$ & $1.30^{\mathrm{ns}}$ & $3.03^{* *}$ & $1.72^{\mathrm{ns}}$ & $0.15^{\mathrm{ns}}$ & & & $11.2 \pm 3.5$ \\
\hline Wsom $3.62^{* * *}$ & $1.65^{\mathrm{ns}}$ & $1.46^{\mathrm{ns}}$ & $0.60^{\mathrm{ns}}$ & $1.99^{*}$ & $0.71^{\mathrm{ns}}$ & $0.90^{\mathrm{ns}}$ & $1.04^{\mathrm{ns}}$ & & $9.8 \pm 3.8$ \\
\hline Ator $4.90^{* * *}$ & $2.99^{* *}$ & $3.50^{* * *}$ & $1.93^{*}$ & $3.25^{* *}$ & $1.98^{*}$ & $0.45^{\mathrm{ns}}$ & $0.30^{\mathrm{ns}}$ & $0.95^{\mathrm{ns}}$ & $11.6 \pm 3.8$ \\
\hline Falb & Apre & Asal & Ckir & Asey & Cocc & Tvil & Dang & Wsom & \\
\hline
\end{tabular}

The mean viability is expressed as the mean number of seeds that remained viable during the five periods of exhumation. The symbols are: $\mathrm{ns}=$ not significant, ${ }^{*} \mathrm{p}<0.1,{ }^{* *} \mathrm{p}<0.05$ and $* * * \mathrm{p}<0.01$. Falb $=$ Faidherbia albida $;$ Apre $=$ Abrus precatorius $;$ Asal $=$ Acacia saligna $;$ Ckir $=$ Crotalaria kirkii $;$ Asey = Acacia seyal; Cocc = Cassia occidentalis; Tvil = Tephrosia villosa; Dang = Dodonaea angustifolia $;$ Wsom = Withania somnifera \& Ator = Acacia tortilis

Group II- This category consists of five leguminous species with intermediate viabilities between Groups I and III. Although all have hard seed coats, they are likely to possess enforced dormancy imposed by water scarcity and therefore have short-term persistent seed banks, which become exhausted by germination in response to rainfall.

Group III- This is a group of three legumes, one species of Sapindaceae and one of Solanaceae. Except for Withania somnifera (Solanaceae) which does not possess impermeable seed coat but probably physiologically-dormant embryo, all others are hard-seeded. The seeds remained ungerminated in the soil and did not respond to wet conditions in the soil. However, in the greenhouse germination experiments, $100 \%$ germination of all legume seeds in this Group and Dodonaea angustifolia (Sapindaceae) could be achieved six months later when subjected to mechanical scarification, indicating that they possessed seed coat dormancy and therefore are able to form persistent seed banks. Both Groups II and III have smooth seeds with no dispersal appendages. 


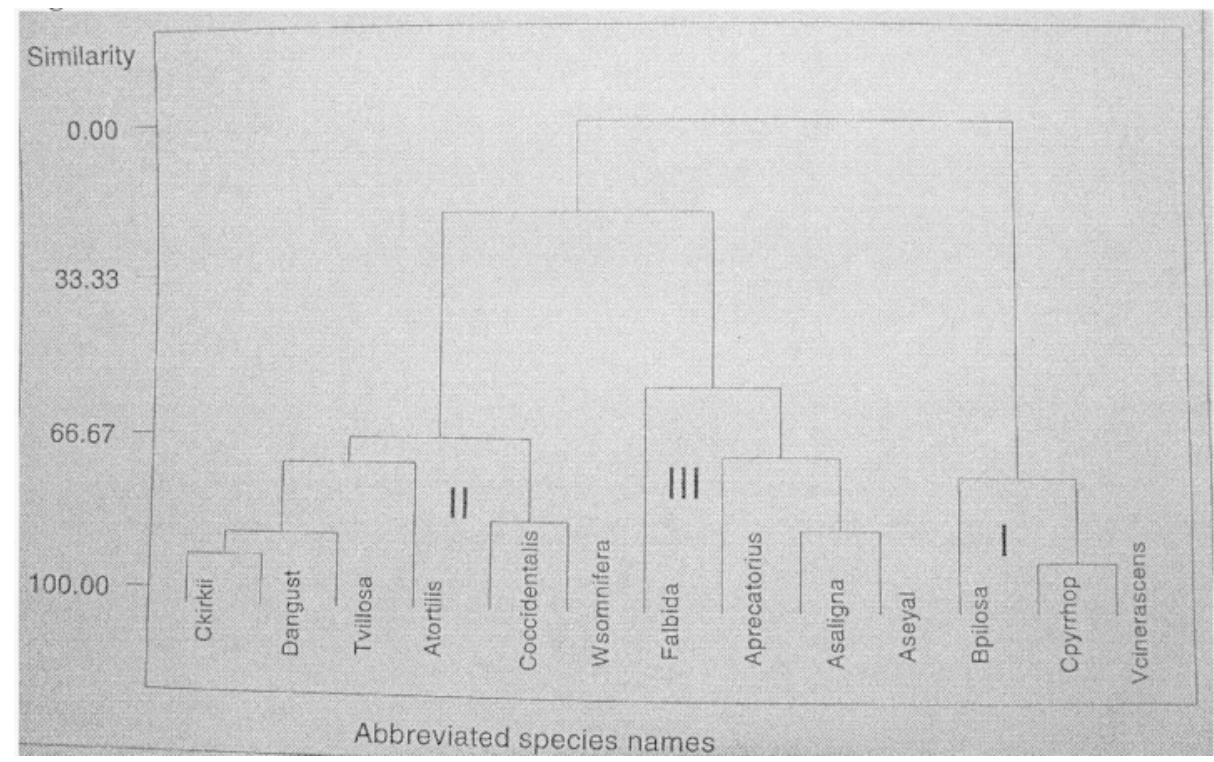

Figure 2: Dendrogram from hierarchical cluster analysis showing the three main clusters among the species studied. Group I are species with no seed dormancy, group II is an intermediate category of the two groups and group III are species with seed coat imposed dormancy.

\section{Seed survivorship versus seed decay patterns}

For all species studied, Table 2 gives the constants $(\mathrm{g})$ that determine rates of loss of seeds in the soil and their half-lives. Since it is assumed that seeds buried under natural conditions exhibit exponential decay in the soil, the parameter half-life quantifies the time required by viable seeds of any species to be reduced by half their original numbers. Species with persistent seed banks are associated with very low decay constants. The pattern of decay of seeds among the composites could not be established as no single seed survived burial conditions during the first three months. Group II species showed very little variations in their half-lives but a remarkable difference in their rates of deterioration in the soil. Group III species had a contrasting pattern to group II in terms of their decay constants and halflives. Four species, Abrus precatorius, Acacia saligna, Acacia seyal and Faidherbia albida, conformed to the agreed pattern of exponential decay in the soil. The species belong to group II of the cluster analysis and have short persistence in the soil. Species belonging to group III, i.e. Acacia tortilis, Crotalaria kirkii, Dodonaea angustifolia and Tephrosia villosa, showed irregular survivorship patterns in the soil and for Crotalaria kirkii seeds the pattern is slightly different from the other two groups. Both Withania somnifera (from Group III) and Cassia occidentalis (group II) slightly conform to the exponential seed decay pattern. 
Table 2: Summarised information of species capable of surviving at least the first three months of burial, arranged in the decreasing order of their half-lives.

\begin{tabular}{llccc}
\hline Species name & Variance & $\begin{array}{c}\text { Decay } \\
\text { Constant }\end{array}$ & $\begin{array}{c}\text { Half life } \\
\text { days }\end{array}$ & $\begin{array}{c}\text { Regresion } \\
\text { equation }\end{array}$ \\
\hline Abrus precatorius & 0.0 & $0.401 \pm \mathrm{nd}$ & 52 & $\mathrm{~S}=20 \mathrm{e}^{-0.401 \mathrm{t}}$ \\
Acacia saligna & 0.04 & $0.257 \pm 0.009$ & 81 & $\mathrm{~S}=24.6 \mathrm{e}^{-0.257 \mathrm{t}}$ \\
Acacia seyal & 0.004 & $0.348 \pm 0.029$ & 63 & $\mathrm{~S}=26.3 \mathrm{e}^{-0.348 \mathrm{t}}$ \\
Acacia tortilis & 0.06 & $0.032 \pm 0.001$ & 662 & $\mathrm{~S}=19.9 \mathrm{e}^{-0.032 \mathrm{t}}$ \\
Cassia occidentalis & 0.08 & $0.186 \pm 0.065$ & 114 & $\mathrm{~S}=25 \mathrm{e}^{-0.186 \mathrm{t}}$ \\
Crotalaria kirkii & 0.002 & $0.055 \pm 0.061$ & 388 & $\mathrm{~S}=16.2 \mathrm{e}^{-0.055 t}$ \\
Dodonaea angustifolia & 0.007 & $0.067 \pm 0.005$ & 340 & $\mathrm{~S}=20.3 \mathrm{e}^{-0.067 t}$ \\
Faidherbia albida & 0.09 & $0.536 \pm \mathrm{nd}$ & 41 & $\mathrm{~S}=20 \mathrm{e}^{-0.536 \mathrm{t}}$ \\
Tephrosia villosa & 0.03 & $0.054 \pm 0.014$ & 483 & $\mathrm{~S}=19 \mathrm{e}^{-0.054 \mathrm{t}}$ \\
Withania somnifera & 0.05 & $0.121 \pm 0.023$ & 187 & $\mathrm{~S}=21.7 \mathrm{e}^{-0.121 \mathrm{t}}$ \\
\hline
\end{tabular}

The decay constants \pm s.e and half-life of seeds in the soil were derived from the relationship $\mathrm{S}=$ $\mathrm{S}_{\mathrm{o}} \mathrm{e}^{\mathrm{-gt}}$ (Roberts and Dawkins 1967). nd stands for not determined. S predicts the number of seeds that will be viable at time $t$

\section{DISCUSSION}

\section{Causes of viability loss}

Under natural conditions in the soil, seed longevity is a result of complex interaction between seeds and environmental factors such as light, moisture, temperature, carbon dioxide levels and oxygen (Cook 1980). Lethal or in situ germination, which was the most important cause of viability loss among the buried seeds of Acacia seyal, Cassia occidentalis, Acacia saligna and Faidherbia albida, is an indication that such seeds have enforced dormancy resulting from water stress, and that they quickly respond to germination in the presence of moisture. Although some seeds of Cassia occidentalis germinated promptly, a high proportion of seeds remain ungerminated for long periods of time, emphasizing the presence of individual variations in seed dormancy. Fenner (1985) reported 13\% loss of buried seeds of Bidens pilosa due to lethal germination. Elsewhere, research has shown that lethal germination could account up to $85 \%$ mortality of buried seeds (Schafer and Chilcote 1970). The ecological interpretation of the behaviour of the four species is that they are unlikely to form persistent seed banks and therefore their survival is critically dependent on the disturbance in the established vegetation, their annual seed production (O'Connor 1991) and escape from other fates of seeds in the soil such as predation. For unpredictable ecosystems such as that in the $\mathrm{KIH}$, this implies that any major catastrophe that eliminates the established plants or untimely germination of seeds, may drive these species to extinction, assuming that no seeds are dispersed into the area.

Other losses due to insect infestation common among Acacia tortilis, Crotalaria kirkii, Dodonaea angustifolia and for all Acacia species worldwide (Kaarakka 1996) have been reported in the literature, where bruchids are the dominant predators (Ernst et al. 1989, Miller 1994). The composites that did not survive burial conditions in the soil succumbed to fungal infection and probably physiological ageing.

\section{Seed viability and cluster delimitation in relation to seed dormancy}

The more spherical seeds had higher viabilities than elongated seeds, an observation that is in agreement with the hypothesis that seed longevity and possession of long-lived seed banks are properties associated with small and 
compacted seeds due to their ease of infiltrating into the soil (Thompson et al. 1993).

Species from Group I of the cluster analysis possess seeds without any kind of dormancy. The species are further characterised by production of numerous seeds having dispersal appendages as an adaptation to ensure effective dispersal and successful colonisation.

Seeds from Groups II and III possess different levels of dormancy conferred by hard seed coats. Literature indicates that such type of dormancy is common among members of the families Leguminosae, Sapindaceae, Geraniaceae etc. (see Murdoch and Ellis 1992). Although Acacia saligna, Acacia seyal, Cassia occidentalis and Faidherbia albida (Group II) have hard testa, the fact that they responded to moisture during the rainy season by in situ germination implies that seed coat impermeability is not the cause of their delayed germination, but might be due to enforced dormancy imposed by water stress. For Group III species, hard-seededness that prevents seed imbibition is one of the regulators of viable seed populations in the soil. Many Acacia species are an important source of food for grazing ungulates and browsers during the dry season in savannas, where massive consumption of pods and seeds has been reported (Pellew and Southgate 1984, Mwalyosi 1990, Miller 1994). The extent of removal of pods and seeds may greatly influence the dynamics of viable seeds in the soil. Their persistence in the soil makes this group the most reliable component of rehabilitating degraded savannas.

\section{Seed bank persistence among Acacia} species

There is considerable literature citing the ability of several species of Acacia to accumulate large seed banks which may persist for many years in semi-arid areas (Holmes 1989, Tybirk et al. 1994).
However, the present study and other previous seed bank studies from the study area do not support these findings. For example, from 120 soil samples of $206 \mathrm{~cm}^{3}$ each (sampled at $0-5 \mathrm{~cm}$ depth), studied using soil sieving and sorting technique, only one viable seed of Acacia tortilis was found (Skagerlund 1998). From another seed bank study using the seedling emergence method, (Lyaruu and Backéus unpublished data), no single Acacia seed was found in any of 540 soil samples of $206 \mathrm{~cm}^{3}$ each (sampled at $0-5 \mathrm{~cm}$ depth). Therefore, it follows that, from the very low calculated values of seed half-lives among Acacia species in this study, except for Acacia tortilis (Table 2), it is unlikely that Acacia seeds may remain viable in the soil for a long time. Both pre- and post-dispersal seed predation have been shown to account for huge losses of seed viability in the study area (Skagerlund 1998). Therefore, even in the presence of physical dormancy among Acacia species, their possibility of accumulating large seed reserves in the soil in arid environments is unlikely due to heavy seed predation and severe losses of seeds incurred when pods and seeds are consumed by ungulates.

\section{CONCLUSIONS}

- Not all legumes possess seed coat imposed dormancy. The present study has shown that among the legumes studied, Abrus precatorius, Acacia saligna, Acacia seyal, and Faidherbia albida germinate promptly in the presence of moisture. For species whose seeds are heavily predated, prompt germination may be interpreted as a survival strategy to avoid predation.

- The extended distribution of germination in the soil shown by Acacia tortilis, Cassia occidentalis, Crotalaria kirkii, Dodonaea angustifolia, Tephrosia villosa and Withania somnifera, is explained by seedto-seed variations in dormancy within the same species. This is an important strategy that prevents pre-emption of the seed bank through synchronous germination and is 
useful in maintaining uniform populations among species in the vegetation.

- There is no evidence from the present study or from other previous seed bank studies conducted in the Kondoa Irangi Hills to support the idea that Acacia seeds form large persistent seed banks. Observations such as the existence of high levels of seed predation (Skagerlund 1998), relatively high decay rates, and prompt germination of seeds in response to rainfall, eliminate the possibility of seed persistence in the soil in this ecosystem for a long time. Moreover, Acacia pods and seeds are consumed heavily by many ungulates during the dry season.

\section{ACKNOWLEDGEMENTS}

I would like to thank Dr. Ingvar Backéus and Prof. Eddy van der Maarel for reviewing the manuscript. I acknowledge the assistance provided in the field and in the greenhouse by $\mathrm{Mr}$ Haji Suleiman and Mr. Mathew Orgenes. This study was financed by a grant from the Swedish International Development Authority (Sida/SAREC) through MALISATA Project.

\section{REFERENCES}

Bakker JP 1989 Nature management by grazing and cutting. Kluwer, Dordrecht.

Christiansson $\mathrm{C}$, Mbegu $\mathrm{AC}$ and Yrgård $\mathrm{A}$ 1993 The Hand of Man: Soil Conservation in Kondoa Eroded Area, Tanzania. Sida's Regional Soil Conservation Unit, R. S. C. U., Report No. 12, 1-55.

Cook R 1980 The biology of seeds in the soil. In: Demography and evolution in plant population.(Ed. O. T. Solbrig). Blackwell Scientific Publications, Oxford.

Demel Teketay and Granström A 1997 Seed viability of Afromontane tree species in forest soils. J. Tr. Ecol. 13: 81-95.

Ernst WHO, Tolsma DJ and Decelle JE 1989 Predation of seeds of Acacia tortilis by insects. Oikos 54: 294-300.

Fenner M 1985 Seed ecology. Chapman \& Hall, London.
Harper JL 1957)The ecological significance of dormancy and its importance in weed control. Proceedings of the 4th International Conference on Plant Protection, Hamburg.

Holmes PM 1989 Decay rates in buried alien Acacia seed populations of different density. S. Afr. J. Bot. 55: 299303.

Kaarakka V 1996 Management of bushland vegetation using rainwater harvesting in eastern Kenya. Acta Forestalia Fennica 253: 1-93.

Kivilaan A and Bandurski RS 1981 The 100 year period for Dr. Beals seed viability experiment. Am. J. Bot. 68: 1290-1292.

Lyaruu HVM 1995 Seed bank dynamics of the formerly overgrazed Kondoa Irangi Hills, central Tanzania: A preliminary report. Working Paper for Environment and Development Studies Unit, Stockholm University 29: 1-12.

Mbegu AC and Mlenge W 1984 Ten years of HADO 1973-1983. Ministry of Natural Resources and Tourism, Forestry Division, Dar Es Salaam.

Miller MF 1994 The fate of mature African Acacia pods and seeds during their passage from the tree to the soil. $J$. Tr. Ecol. 10: 183-196.

MINITAB (1995) MINITAB user's guide. Release 10xtra, MINITAB Inc., USA.

Murdoch AJ and Ellis RH 1992 Longevity, viability and dormancy. In: The ecology of regeneration in plant communities (Ed. M. Fenner). CAB International, Wallingford, UK.

Mwalyosi RBB. 1990 The dynamic ecology of Acacia tortilis woodland in Lake Manyara National Park, Tanzania. Afr. J. Ecol. 28: 189-199.

Ngana JO 1992 Climatic assessment of Kondoa Eroded Area. Institute of Resource Assessment, University of Dar Es Salaam. Research Report No. 80.

O'connor TG 1991 Local extinction in perennial grasslands: a life-history approach. Am. Nat. 137: 753-773. 
Pellew RAP and Southgate BJ 1984 The parasitism of Acacia tortilis in the Serengeti. Afr. J. Ecol. 22: 73-75.

Roberts, E. H. (1963) An investigation of inter-varietal differences in dormancy and viability of rice seeds. Ann. Bot. 27, 365-369.

Roberts EH 1972 Viability of seeds. Chapman \& Hall, London.

Roberts HA 1981 Seed banks in soils. $A d v$. Appl. Biol. 6, 1-55.

Roberts HA and DAWKINS PA 1967 Effect of cultivation on the numbers of viable weed seeds in soil. Weed Res. 7, 290301.

SAS 1990 SAS User's Guide: $5^{\text {th }}$ Edition. SAS Institute, Cary, NC.

Schafer DE and Chilcote DP 1970 Factors influencing persistence and depletion in buried seed populations. II. The effects of soil temperature and moisture. Crop Sci. 10, 342-345.

Skagerlund K 1998 The fate of seeds in five legume tree species in woodlands of
Kondoa Irangi Hills, Tanzania. Arbetsgruppen för Tropisk Ekologi Report. Uppsala University.

Thompson K, Bakker JP and Bekker R 1997 The soil seed banks of North West Europe: methodology, density and longevity. Cambridge University Press, Cambridge.

Thompson K, Band SR and Hodgson JG 1993 Seed size and shape predict persistence in soil. Funct. Ecol. 7, 236241.

Thompson K and Grime JP 1979 Seasonal variation in the seed banks of herbaceous species in ten contrasting habitats. $J$. Ecol. 67: 893-921.

Tsuyuzaki S 1991 Survival characteristics of buried seeds 10 years after the eruption of the Usu volcano in northern Japan. Can. J. Bot. 69: 2251-2256..

Tybirk K, Schmidt LH and Hauser T 1994 Notes on soil seed banks of African acacias. Afr. J. Ecol. 32: 327-330. 